\title{
DELIVERING SUSTAINABILITY THROUGH SUPPLY CHAIN DISTRIBUTION NETWORK REDESIGN
}

\author{
Ravet, D.
}

Purpose: Companies could gain (cost, service, green/sustainable) a competitive advantage through the supply chain network. The goal of this article is to study how to deliver sustainability through the redesign of the supply chain distribution network.

Design/methodology/approach: A literature review is conducted to examine research relating to sustainable supply chain strategies and the redesign of the supply chain distribution network.

Findings: A study of the supply chain literature reveals the importance of rethinking the supply chain distribution network's design and treating sustainability as an integral part of operations.

JEL Classification: M, M11, R4

Keywords: Global supply chain strategies; sustainable supply chain strategies; distribution network redesign.

\section{Introduction}

Due to the global economy, competitive pressure, the price of crude oil and rising ecology consciousness, the survival of many companies depends on their ability to continuously improve quality while reducing costs in a sustainable way. The mounting pressure to conduct business in a sustainable fashion comes from various stakeholders - customers, shareholders, boards, employees, governments, and non-governmental organizations - and most corporations respond in a reactive, piecemeal way. Instead, companies - throughout the supply chain, not just at the end - should pursue broader structural changes than they typically do. Sustainability issues are adding new challenges to managing global supply chains (Lee, 2010). Indeed, in the wake of concerns regarding climate change, pollution and non-renewable resource constraints, sustainability is becoming a key issue for supply chains.

The sustainability paradigm has opened the gate for revisiting various established strategies of supply chain management to reassess their viability with a new angle of sustainability in general and greening in particular (Stonebraker et al., 2009). For many organizations, sustainability is emerging as a significant business issue. Consumers want the comfort of buying products that are meeting all possible environmental standards. Those that are successful in achieving these standards will see reduced operating costs and create competitive advantage by offering new value to their customers. As stakeholders increasingly demand higher standards, those companies that fail to take action will leave themselves vulnerable to significant business erosion (Bernon, 2009).

In response to globalization, the ever increasing customer demands for variety and rapid delivery at acceptable costs, supply chains have a wide geographical spread and are an excellent vehicle for improving the environmental, social, and economic performance of companies and industry sectors over the long term. From purchasing decisions to reverse logistics, the whole supply chain will be reshaped by these new environmental regulations (McIntyre, 2012).

Business processes have to respond to continuous changes and the sustainability requirement. The competitive and supply chain strategies must take these changes into consideration and companies have been focusing on the reconfiguration of the supply chain network design, especially distribution channels. 
Indeed, network design decisions are among the most important supply chain decisions, as their implications are significant and long lasting. The reconfiguration of the supply network needs to take into account the trends of globalization, with possibly longer total pipelines and local differences in customer requirements (Christopher, 2005). Therefore, the needs of local markets must be balanced against the economic advantage of standardized products. Companies have to combine global efficiency, local responsiveness and a capability to share and develop knowledge management worldwide. Besides, sustainability has become a key priority in the design and operation of supply chains (Chopra and Meindl, 2012). A focus on sustainability allows a supply chain to better serve more environmentally conscious customers while often improving supply chain performance. Consequently, in this context, how is it possible to deliver sustainability through the supply chain distribution network?

The purpose of this study is to present how to deliver sustainability through the distribution network redesign. First, we will present the impact of supply chain strategies on the distribution network, and then we will identify how to redesign the distribution network.

\section{Globalization and Supply Chain Strategies}

The purpose of this first part is to present the link between global supply chains and green/sustainable supply chains and the distribution network.

\section{Globalization}

Markets have become global in the sense that the same brands and products are increasingly offered for sale around the world. Equally apparent has been the move towards global sourcing and manufacturing as companies concentrate their operations on a few factories that serve the whole world and thus there are interdependencies of suppliers and customers among international companies. The global company has revised its previously localized focus, manufacturing and marketing its products in individual countries, and now instead will typically source on a worldwide basis for global production and distribution. The logic of the global company is clear: it seeks to grow its business by extending its markets whilst at the same time seeking cost reduction through scale economies in purchasing and production through focused manufacturing and/or assembly operations.

The trend toward globalization has a central role to play in supply chain management and has increased the complexity of the value chain with longer pipelines. Therefore, globalization through a global strategy is affecting the supply chain's structures and processes and will continue to be a pivotal issue in the context of supply chain management (Christopher, 2005).

\section{Definition of Supply Chain Strategies}

In the early 1980 s, firms realized that their competitiveness was not just determined by what they do, but also by what their upstream suppliers and downstream suppliers were doing. Supply chain capabilities are a significant determinant of competitiveness and it can be argued that value chains compete, not individual companies (Christopher, 2000). The key point in supply chain management is to consider the entire system of suppliers, manufacturing plants, and distribution tiers. Supply chain management can be defined as a set of interdependent organizations that act together to control, manage and improve the flow of materials, products, services and information, from the point of origin to the delivery point (the end customer) in order to satisfy customer needs at the lowest possible cost to all members (Lambert, Stock, and Ellram, 1998). The supply chain is a group of partners who collectively convert a basic commodity (upstream) into a finished product (downstream) that is valued by end customers, and who manage returns at each stage (Harrison and Van Hoek, 2005).

A supply chain consists of all parties involved, directly or indirectly, in fulfilling a customer request. The supply chain includes not only the manufacturer and suppliers, but also transporters, warehouses, retailers, and even customers themselves. Within each organization, such as the manufacturer, the supply chain includes all functions involved in receiving and filling a customer request. These functions include, but are not limited to, new product development, marketing, operations, distribution, finance, and customer service (Chopra and Meindl, 2010).

It highlights the reverse logistics and its importance in the supply chain. The success or failure of a supply chain is ultimately determined in the marketplace by the end consumer. Customer satisfaction and marketplace understanding are crucial elements for consideration when attempting to establish a new supply chain strategy. When the requirements and constraints of the marketplace are understood, can an enterprise attempt to develop a strategy that will meet the needs of both the supply chain and the end customer?

"Logistic strategy is the set of guiding principles, driving forces and ingrained attitudes that help to coordinate goals, plans and policies, and which are reinforced through conscious and subconscious behavior within and between partners across a network" (Harri- 
son and van Hoek, 2011, p. 7). A supply chain strategy determines the nature of procurement of raw materials, transportation of materials to and from the company, manufacture of the product or operation to provide the service, and distribution of the product to customer... (Chopra and Meindl, 2010). Supply chain strategy encompasses long-term objectives and it is derived from the company's or business unit's overall strategy (AT Kearney, p. 18).

Aligning markets requirements with supply chain capabilities through supply chain strategy creates a competitive advantage (Hoffmann, 2010). Consequently, the primary purpose of any supply chain is to satisfy customer needs and, in the process, generate profit for itself. Therefore, the goal of supply chain strategy is to strike the balance between responsiveness and efficiency that fits with the competitive strategy. To reach this goal, a company must structure the right combination of the three logistical drivers (facilities, inventory and transportation) and three cross-functional drivers (information, sourcing and pricing). For each of the individual drivers, supply chain managers must make a trade-off between efficiency and responsiveness based on interaction with the other drivers. The combined impact of these drivers then determines the responsiveness and the profits of the entire supply chain (Chopra and Meindl, 2010). Therefore, to understand how a company can improve supply chain performance in terms of responsiveness and efficiency, we must examine the logistical drivers like facilities, inventory and transportation drivers.

Several supply chain strategies are possible in order to respond to an increasingly complex business environment:

- Global supply chain strategies,

- green/sustainable supply chain strategies.

\subsection{Global Supply Chain Strategy}

\section{Origins}

Globalization may enable increased revenue generation through entry into new markets and may provide access to suppliers that can provide materials and inputs more efficiently than domestic sources. There has also been an increasing trend for firms to shift from the host country to lower cost geographies to reduce manufacturing costs (Mollenkopf et al., 2010).

Firms implement global strategies that imply an overall approach and the focus on standardization, similarities and synchronization on a worldwide basis (Andersson and Svensson, 2009). "A global strategy seeks to maximize worldwide performance through sharing and inte- gration...” (Yip, 1992, p. 31). A global strategy, like global sourcing and offshore manufacturing, alters the landscape of business activity; there needs to be a similar change in the way in which supply chain strategies are determined.

\section{Global Supply Chain Strategies Definition}

The logistics dimension of internationalization conjures up a vision of parts flowing seamlessly from suppliers to customers located anywhere in the world, and a supply network that truly spans the entire globe (Harrison and Van Hoek, 2011). Firms have restructured their supply chains to "operate on a global basis to take advantage of the international product, factor, and capital markets" (Manuj and Mentzer, 2008, p. 133). The globalization of supply chains involves dimensions such as offshoring of production, inventories, suppliers and customers, and differences in economies, infrastructure, cultures and politics in the competitive environment (Mollenkopf et al., 2010; Manuj and Mentzer, 2008; Schmidt and Wilhelm, 2000; Christopher, 2005).

\section{Global Supply Chain Strategies and Network Design}

Global supply chain management presents several challenges, including differences in economic, cultural, and regulatory environments. Global supply chain literature emphasizes especially the importance of the complexity and coordination involved in managing the consolidation and regionalization of the supply chain network (Christopher, 2005).

\subsection{Innovative Supply Chain Distribution Network Configuration: The Link between Global and Local Markets}

Consequently, whilst the logic of globalization is strong, it is important to recognize that it also presents certain challenges. Specially, world markets are not homogeneous; there is still a requirement for local variation in many product categories, and products may need certain customization to meet specific-country needs (Christopher, 2005). Corporate and global strategies are linked to supply chain strategies and capabilities, especially on the network level (Hofmann, 2010).

In addition, critical competitive advantages can be harnessed by consolidating and regionalizing the supply chain. The trend towards sustainability today clearly underscores the intensified regionalization of supply chains worldwide. Experts forecast that sustainability will gain further in importance, which will foster the application of CO2-efficient modes of transportation (AT Kearney, 2009). 


\section{Definition}

Network design decisions are among the most important supply chain decisions, as their implications are significant and long lasting (Chopra and Meindl, 2010). Network design is a strategic decision that has a long-lasting effect on the firm (Simchi-Levy, 2008).

The physical supply chain consists of suppliers, plants, warehouses, distribution centers, and retail outlets as well as raw materials, work-in-process inventory, and finished products that flow between the facilities (Simchi-Levy, 2008).

Supply chain network design decisions determine the physical configuration and infrastructure of the supply chain. It includes the assignment of facility role, location of manufacturing, storage, or transportation-related facilities, and the allocation of capacity and markets to each facility (Chopra and Meindl, 2010).

Moreover, according to Gunasekaran (2001), perhaps the most important research concerning logistics that is going on is in the area of designing efficient and cost-effective distribution systems. Indeed, the distribution network takes on a wider role as the provider of the final added value. What is apparent is that distribution in the integrated supply chain has now become an information-based, value-added activity, providing a critical link between the market place and factory (Christopher, 2009). Distribution refers to the steps taken to move and store a product from the supplier stage to a customer stage in the supply chain. Distribution is a key driver of the overall profitability of a firm because it directly affects both the supply chain cost and the customer experience An appropriate distribution network can be used to achieve a variety of supply chain objectives ranging from low cost to high responsiveness (Chopra and Meindl, 2010).

\section{Strategy}

Based on the competitive strategy of the firm, its resulting supply chain strategy must determine the supply chain's design for the firm. The supply chain strategy specifies what capabilities the supply chain network must have to support the competitive strategy. A firm must ensure that the supply chain's configuration supports its strategic objectives and maximizes the overall supply chain surplus (customer value minus supply chain cost) generated (Chopra and Meindl, 2010).

Ideally, organizations would like to achieve the benefits of standardization in terms of cost reduction whilst maximizing their marketing success through localization (Christopher, 2005). Consequently, in response to globalization, the ever increasing customer demands for variety and rapid delivery at acceptable costs, companies search for innovative configuration of the supply chain network especially for locating activities. Thus, the challenge of facilities location is to structure a supply chain that balances between global efficiency and local responsiveness and which best supports the company's competitive strategy and maximizes competitive advantage. This is especially the case for facilities location relating to the distribution network as it delivers to the local markets.

Moreover, facilities tend to be significant consumers of energy and water, and emitters of waste and green-house gases - thus they offer significant opportunities for profitable improvement (Chopra and Meindl, 2012). Transportation is another driver wherein firms are likely to find several positive cash flow opportunities. Any supply chain design innovation that lowers transportation costs also tends to reduce emissions and waste generated from transportation. This improvement through increased aggregation, a more efficient loading of transportation vehicles, and an increase in their fuel efficiency cuts both costs as well as environmental damage (Chopra and Meindl, 2012). These improvements are linked to green/ sustainable supply chain strategies evolution.

\subsection{Green/Sustainable Supply Chain Strategies}

The sustainability issue will be taken into account to formulate the future supply chain strategy. It is now on the corporate agenda of 60 percent of all participating companies. Experts see a clear need for action here. Not only sustainability must be understood as an important "to do" but also as an imperative for day-to-day operations in order to generate value by achieving sustainability (AT Kearney, 2009).

\section{Origins}

Interest in sustainable supply chains has been growing for over a decade and the topic is becoming mainstream (Corbett and Kleindorfer 2003; Corbet and Klassen 2006). Organizations need to deal with both environmental and social issues (e.g. Kleindorfer, Singha and Van Wassenhove 2005; Corbett and Klassen 2006). Sustainability is about ensuring the long-term viability of a business model and company. Shareholders, customers, suppliers and employees, all want to see a future in their businesses (McIntyre, 2012).

\section{Sustainability Definition}

The Brundtland Commission (World Commission on Environment and Development 1987, p.8) defined the term 'sustainability' as: "the development that meets the 
needs of the present without compromising the ability of future generations to meet their own needs".

Corporate sustainability has been focused with attention drawn toward the triple bottom line of "people, profit and planet" and promotes the view that companies have a responsibility to look beyond profit maximization and take responsibility for their environmental and social performance (Elkington, 1994). The "people element refers to the fair treatment of individuals that the organization either directly employs or interfaces with across its supply chains. Planet considers the impacts an organization's activities have on the environment. Finally, profit is the economic benefit obtained by society through commercial activity (Bernon, 2009). The study focuses mainly on the planet and profit pillars and equally on corporate sustainability, which has been defined as a business approach that creates long-term shareholder value by embracing the opportunities and managing the risks associated with economic, environmental and social developments (Elkington, 1994).

\section{Sustainable Supply Chain Strategies}

The sustainability paradigm may have influence on the supply chain and many supply chain decisions may have impacts on the environment, the social aspects, the communities and the wider supply chain. Three distinct phases of supply chain are identified in the literature (Shukla, 2004):

- Inbound supply chain ensures value addition to raw materials in terms of selection, segregation, packing, transportation, cold storing, warehousing... There are a host of intermediate echelons like consolidators, traders, commission agents, wholesalers, retailers, and third party logistics, which results in very high complexity. It implies a green-design, green sourcing... Greening the supply chain generates environmental benefits as well as financial results by reducing risk by managing a product's environmental compliance in its design rather than making any necessary costly corrections later in its lifecycle.

- Manufacturing supply chain or internal supply chain: value addition is done during manufacturing or production of goods. Functions like material flow, material handling and inventory management are predominant and imply green manufacturing.

- Outbound supply chain: the distribution channel operations like warehouse location, mode of transportation and inventory management at retail and wholesale level... it implies green logistics and green reverse logistics. The study focuses on outbound supply chains.
The distribution channel includes the transport and warehousing operations across the supply chain network. One of the major issues for transport is associated with emissions from freight movement; it is also projected that this figure is likely to increase. In addition, in recent years, the movement of goods has shifted away from the less polluting transport modes of sea and train to road and air (Bernon, 2009). From an environmental perspective, all firms should measure and report four categories:

- Energy consumption,

- water consumption,

- greenhouse gas emissions,

- waste generation.

The opportunity to improve supply chain sustainability is by matching these categories with the supply chain drivers like transportation and facilities (Bernon, 2009). Several solutions can be adopted - driver training, maintenance of vehicle fleets, alternative fuels and so on - that reduce not only the emissions of vehicles, but also operating costs. However, sustainability issues are adding complexity and risks to the already large challenge of managing supply chains such as inventory, cycle time, quality, the costs of materials, production and logistics (Lee, 2010).

\section{The Distribution Network Re-engineering}

\subsection{The Origins of the Distribution Network Reconfiguration}

New forces and dynamics are emerging to influence the supply chain designs of the future (Simchi-Levi and Fine, 2010). Globalization and sustainability can change the firm's supply chain strategy (Waters, 2012).

As a firm must ensure that the physical supply chain's configuration supports its strategic objectives, the distribution network must be reconfigured according to all these factors and warehouse costs, number and location of distribution center (Shang and al. 2009).

The supply chain's infrastructure typically needs to be re-evaluated due to changes in supply chain strategy, demand patterns, product mix, production processes, sourcing strategies, the cost of running facilities and sustainability (Simchi Levi, 2008). Six main trends affecting supply chain designs have been identified by Simchi and Fine (2010): globalization, increase in logistics costs, in the level of risk, in labor cost in developing countries, in the volatility of commodity, and the focus on sustainability. It's especially acute in Europe with the green supply chain. In some industries, this will play out as an increase in regulations that companies have 
to follow, and will require thinking about how much carbon your supply chain produces (Simchi-Levi and Fine, 2010).

Thus, delivery network and workplaces must conform to recognized international standards. A major strength is a significant home delivery network with the ability to facilitate the recycling of goods, helped by an efficient "reverse logistics" capability. The rapid development of new technology creates increasingly high levels of hazardous electronic and electrical waste which is the background for the WEEE Directive. Its aim is to minimize the impact of electrical equipment on the environment when those products become waste. In order to sell products within the EU, manufacturers must demonstrate compliance with the regulations. This means that electrical retailers must offer take back facilities to cover all categories including smaller appliances. Some companies offer to take away two items for recycling free of charge if it makes a home delivery for large white goods. The collection items are sorted in several collection sites where they are dismantled.

The European Waste Electrical and Electronic Equipment (WEEE) Directive will have a significant and long reaching effect on the supply chain. Waste electrical and electronic equipment is one of the priority waste streams identified by the European Commission alongside batteries, types, vehicles and packaging. Therefore the general objectives of the WEEE legislation are to improve waste management processes, eliminate hazardous substances, increase recycling capacity and introduce harmonizing legislation (McIntyre, 2012).

Cooper, Browne and Peters (1991) maintain that the transport and storage of goods are at the center of any logistics activity, and these are areas where a company should concentrate its efforts to reduce its environmental impacts. The use of combined transport options such as containers using road and rail links is advocated for environmental improvement.

Therefore, in addition, as a further environmental measure, the goal is to minimize the emissions from the transport operations. It implies modification of the logistics operation to achieve a more efficient use of the transport fleet; many operating companies make use of satellite navigation systems to improve their delivery schedules. This not only reduces the distance the vans and lorries travel but also provides their customers with more predictable arrival times. Initiatives like driver training are implemented with the aim of reducing fuel consumption and $\mathrm{CO} 2$ emissions. Further savings have come from the introduction of new delivery vehicles with Euro 5 engines and "stop and start" technology.
Increased use of call centers has also led to less vehicle journey to customer homes, not only improving the customer service, but also reducing the $\mathrm{CO} 2$ emissions. In addition, the goal is also to reduce the amount of packaging used and to ensure that it can be recycled. Companies collect all waste packaging when delivering a household appliance unless the customer requests otherwise. Consequently, redesigning the network could particularly help the company:

- To meet sustainability goals,

- to minimize the total distribution costs and to improve the customer service levels, and

- to manage growth in operations while maintaining quality and service levels.

Although sustainability measures often seem worthwhile individually, they may in the grand scheme generate unintended consequences, such as higher financial, social, or environment costs (Lee, 2010). Consequently, these sustainability measures must be coordinated across every stage of the supply chain with adjacent operations. Thus, the development of sustainable has tended to focus on studies of a single function or activity as opposed to looking at the entire chain (Rao and Holt, 2005). But, companies - throughout the supply chain, not just at the end - should take a holistic approach to sustainability and pursue broader structural changes than they typically do. This is mainly important in an international supply chain.

\subsection{The Ways of Reconfiguration}

The imperatives of cost efficiency and customer responsiveness have pushed firms to aggressively pursue two business strategies: global location of production/distribution facilities and time-based competition. Both of these strategies have dramatically transformed the way in which business activities are organized and carried out. But the chief difficulty that a firm faces in the implementation of these strategies is that they make somewhat contradictory demands on its resources (Bhatnagar and Viswanathan, 1999). It seems relevant to categorize reconfiguration tendencies. Two generic tendencies can be found: a reconfiguration in the direction of globalization involving an upstream positioning of operations and a reconfiguration in the direction of localization involving a downstream positioning of operations. Consequently, there are more sensible, hybrid approaches to supply chain management that combine regional and global activities (Simchi Levi and Fine, 2010).

Cooper, Browne and Peters (1991) suggest a three-stage approach to improve the processes: an environmental 
audit of the logistics operation, a listing of actions to reduce impacts and a priority ranking of these actions. The problem with these recommendations is that they are not stakeholder-focused, but look only at fuel consumption an economic cost (Mc Intyre, 2012).

As specified before, to achieve strategic fit, a company must ensure that its supply chain capabilities support its ability to satisfy the targeted customer segments. A network designer needs to consider the strategic position, the product characteristics as well as network requirements when deciding on the appropriate delivery network; the methodology suggested by Chopra and Meindl (2010) is described as follows:

- Understanding the customer: first, a company must understand the customer needs for each targeted segment and the uncertainty these needs impose on the supply chain. These needs help the company define the desired cost and service requirements. The supply chain uncertainty helps the company to identify the extent of the unpredictability of demand, disruption, and delay that the supply chain must be prepared for (range of quantity required, lead time customer, variety of products, number of channels, service level required...).

- Understanding the supply chain capabilities: there are many types of supply chains, each of which is designed to perform different tasks well. A company must understand what its supply chain is designed to do well. It is important to discuss the strengths and weaknesses of the various distribution options. Distribution networks that ship directly to customers are better suited for a large variety of high-value products that have low and uncertain demand. These networks carry low levels of inventory but incur high transportation costs and provide slow response times. Distribution networks that carry local inventory are suitable for products with high demand, especially if transportation is a large fraction of total cost. These networks incur higher inventory costs but lower transportation costs and provide a faster response times.

- Achieving strategic fit: if a mismatch exists between what the supply chain does particularly well and the desired customer needs, the company will either need to restructure the supply chain to support the competitive strategy or alter its competitive strategy. Creating strategic fit is all about creating a supply chain strategy that best meets the demand a company has targeted given the uncertainty it faces.

Consequently, at the highest level, performance of a distribution network should be evaluated along two dimensions: customer needs that are met and cost of meeting customer needs when designing the distribution network. Thus, a firm must evaluate the impact on customer service and cost as it compares different distribution network options.

AT Kearney's approach (2011) consists of the following:

- Create a baseline. Redesigning a network requires a clear understanding of how the current product portfolio is positioned in the market, customer requirements, and the maturity of products and processes. All operations strategies begin with the markets. The focus is to analyze market requirements throughout the company's value chain (market complexity versus product maturity for all important product groups to determine the relevant local, regional, or global strategy irrespective of factor costs) to determine the correct balance between factor-cost advantages and transportation costs, to quantify scale advantages... The goal is to consolidate all required information on sales volumes, products, cost structures, headcounts and logistic flows.

- Develop corporate guidelines. Corporate guiding principles and constraints should be discussed in the early stages of every network-design initiative, both as a way to engage decision makers early in the process and to help everyone understand the internal dynamics.

- After gauging strategic fit, implementation feasibility and risks, the company's future network is crafted. The network is developing potential network scenarios. The objective is to chart a master plan in order to test each potential scenario.

Consequently, A.T. Kearney's approach to network design brings together the perspectives of sales, logistics, manufacturing, sourcing, and macroeconomics to develop fully balanced strategies for global competition.

\section{Conclusion}

With the increasing level of volatility and under the pressure of different forces and trends, the days of static supply chain strategies are over (Simchi Levi and Hines, 2010). Supply chain network design must evolve according to supply chain and corporate strategies. The imperatives to deal with global and sustainable supply chain strategies imply reengineering of the distribution network's design. Resolving the contradictions between the requirements of globalization and local market needs in a complex supply chain design and sustainability require one to redesign and manage sustainability as a core operational issue. 
The restructuring of the original supply chain design could improve the overall supply chain's performance. Companies throughout the supply chain, not just at the end, should take a holistic approach to sustainability and pursue broader structural changes than they typically do (Lee, 2010).

According to the importance of this task and the cost related while maintaining the same service level, several strategies could be implemented. Start with restructuring of the original supply chain design on only one distribution channel, one product family or a part of the distribution network in order to test the different actions (the distribution warehouse).

This implies creation or revision of the different supply chain key performance indicators in order to measure the impacts and the evolution of this distribution network reengineering to ensure that all these actions are worthwhile, and are aligned with corporate and sustainable strategies. Database synchronization and data sharing could improve this monitoring with a project management team. Besides, distribution channels network solutions must be built with the main customers interested in a green/sustainable distribution network in order to create a green/sustainable value chain. Building an internal and external team with different partners on an innovative green/sustainable distribution network improves the opportunities to create new sources of competitive advantages.

\section{References}

A.T. Kearney (2009). Managing a Global Supply Chain in a Globally Challenged World. Institute for Supply Chain Management's 94 ${ }^{\text {th }}$ Annual International Conference, USA.

Bhatnagar R., Viswanathan S. (1999). Re-engineering global supply chains. International Journal of Physical Distribution and Logistics Management, 30(1).

Brundtland, G. H. (1987). World commission on environment and development: our common future. Oxford: Oxford University Press.

Chopra, S., Meindl, P. (2010). Supply Chain Management. New Jersey: Pearson.

Christopher, M. (2005). Logistics and Supply Chain Management: Creating Value-adding Networks. New York: Financial Times.

Davila, T., Wouters, M. (2007). An empirical test of inventory, service and cost benefits from a postponement strategy. International Journal of Production Research, 45(10): 2245-2267.
Elkington, J. (1994). Towards the sustainable corporation: win-win-win business strategies for sustainable development. California Management Review, 36(2): 90-100.

Gunasekaran, A., Patel, C., Tirtitoglu, E. (2001). Performance measures and metrics in a supply chain environment. International Journal of Operations and Production Management, 21(1/2): 71-87.

Hofmann, E. (2010). Linking Corporate Strategy and Supply Chain Management. International Journal of Physical Distribution \& Logistics Management, 40(4): 256-276.

Kleindorfer P. R., Shingal K., Ban Wassenhove, L. N. (2005). Sustainable Operations Management. Production \& Operations Management. 14(4): 482-492.

Lee, H. (2010). Don't tweak your supply chain - rethink it end to end. Harvard Business Review, 88(10): 63-66.

Mentzer, J. T. et al. (2001). Defining Supply Chain Management. Journal of Business Logistics, 22(2): 1-25.

Mollenkopf, D. A. (2006). Environmental Sustainability: examining the case for environmentally-sustainable supply chains. Council of Supply Chain Management Professionals, Lombard, IL.

Rao, P., Holt, D. (2005). Do green supply chains lead to competitiveness and economic performance? International Journal of Operations \& Production Management, 25(9): 898-916.

Shang, J., Yildirim, T.P., Tadikamalla, P., Mittal, V., Brown, H. L. (2009). Distribution Network Redesign for Marketing Competitiveness. Journal of Marketing, 73: 146-173.

Shukla, A. C. (2004). Modeling of Intangibles: An application in Upstream Supply Chain (A case study of Service Industry). Unpublished Master Thesis. New Delhi, India: Department of Mechanical Engineering, IIT.

Simchi-Levi, D., Kaminsky, P., Simchi-Levi, E. (2008). Designing and Managing the supply chain. New York: Mc Graw-Hill.

Simchi-Levi, D., Fine, C. H. (2010). Your next supply chain. MIT Sloan Management Review, 51(2): 17-24.

Van Hoek, R.I. (2001): The rediscovery of postponement: a literature review and directions for research. Journal of Operations Management, 19: 161-184.

Author

Denise Ravet, Ph.D.

Doctorate in Management Sciences Teacher in Supply Chain Management IAE Lyon Université Jean Moulin Lyon 3 6 cours Albert Thomas - 69008 Lyon France denise.ravet@univ-lyon3.fr 